\title{
USO DO ESPAÇO E COMPORTAMENTO DOS VISITANTES COMO INDICADOR DE DESEMPENHO DOS ESPAÇOS ABERTOS DE JARDINS ZOOLÓGICOS
}

\section{VISITOR'S USE OF SPACE AND BEHAVIOR AS INDICATOR OF ZOOS OPEN SPACES PERFORMANCE}

\author{
Samantha Balleste \\ Natalia Naoumova
}

\section{Resumo}

Proporcionar um espaço qualificado é considerado essencial para o cumprimento das funções de educação e entretenimento dos jardins zoológicos. No entanto, há carência de estudos que abordem a qualidade espacial nessas instituições, baseados em avaliações envolvendo indivíduos. Assim, esta investigação tem como objetivo verificar como os espaços abertos dos jardins zoológicos são apreendidos e vivenciados, identificando quais elementos físicos-espaciais desses ambientes intensificam o uso do espaço e podem estar relacionados a percepção de qualidade ambiental. O trabalho adota uma abordagem metodológica qualitativa e quantitativa e é conduzido a partir de um estudo de caso, o Parque Zoológico da FZB/RS. O uso e as preferências dos visitantes são considerados como medida de desempenho ambiental.

Palavras-chave: Jardins zoológicos. Espaços abertos. Qualidade ambiental.

\section{Abstract}

Providing a qualified space is considered essential for the fulfillment of the education and entertainment functions of zoos. However, there is a shortage of studies that address spatial quality in these institutions, based on assessments involving people. Therefore, this research aims to verify how the open spaces of zoological gardens are apprehended and experienced, identifying which physical-spatial elements of these environments intensify the use of space and can be related to the perception of environmental quality. The work adopts a qualitative and quantitative methodological approach and is conducted from a case study, the Zoological Park of the FZB/RS. The use and preferences of visitors are considered as environmental performance measures.

Keywords: Zoological gardens. Open spaces. Environmental quality. 


\section{Desempenho dos Espaços Abertos de jardins ZOOLÓGICOS}

Os jardins zoológicos contemporâneos têm como principais finalidades a educação e o entretenimento do público, a conservação das espécies e a realização de pesquisas (HANCOCKS, 2003). A educação e entretenimento dos visitantes são geralmente atribuídos a encontros pessoais com os animais, onde é oferecido aos visitantes a oportunidade de aprendizado sobre as espécies da fauna ameaçadas de extinção e seus habitats, mostrando a importância da biodiversidade e assim levando a um comportamento de conservação. Os animais são considerados importantes recursos para os programas de conscientização da conservação, pois sensibilizam a população sobre os riscos não apenas da sua extinção, mas também dos seus habitats (FIORAVANTI, 2011). Ebenhöh (1992) aponta que embora os animais sejam uma parte importante da experiência, as áreas abertas entre as exposições e lugares convenientes para desfrutar o ambiente são altamente significativos para as pessoas, e tão importantes quanto às exposições em si. Lugares atrativos, com qualidade espacial, tendem a atrair mais indivíduos do que lugares pouco qualificados, pois as pessoas são capazes de reconhecer os lugares mais vantajosos para si (HAAS, 2000). Entende-se que a qualidade da visitação deve ser um dos itens fundamentais no planejamento de jardins zoológicos, pois quando bem qualificados, ou seja, com ambientes dinâmicos e prazerosos, podem possibilitar uma melhor absorção das informações educativas pelo visitante (JONES et al., 1976).

Contudo, evidenciou-se que a literatura pouco descreve como projetar tais espaços, levando em consideração a percepção de seus visitantes. Assim, este estudo trata da necessidade de identificar os aspectos que influenciam no desempenho dos espaços abertos de jardins zoológicos, e seu reconhecimento como um lugar qualificado a partir da percepção dos seus visitantes. Na área de pesquisa das Relações Ambiente-Comportamento a medida de satisfação normalmente é usada para a avaliar o desempenho ambiental. No entanto, vários pesquisadores, entre eles Reis \& Lay (2006), apontam que ela pode não ser uma medida suficien- te para identificar os elementos que influenciam na percepção dos indivíduos. Para determinar quais componentes físicos e simbólicos presentes nos espaços abertos de jardins zoológicos que afetam a percepção e influenciam na avaliação da qualidade desses ambientes, faz-se necessário verificar através da observação comportamental, a efetiva utilização dos espaços. O uso é reconhecido por vários autores como indicador de desempenho para espaços abertos (FRANCIS, 2003; REIS \& LAY, 2006).

Assim, este estudo busca verificar como os espaços abertos dos jardins zoológicos são apreendidos e vivenciados, considerando o comportamento dos visitantes e suas preferências. São identificados quais elementos físicos-espaciais de design estão presentes nesses ambientes e como eles intensificam o uso do espaço, e assim, possam estar relacionados a percepção de qualidade, orientando na definição de critérios de planejamento de futuras intervenções nesses ambientes afim de criar espaços qualificados, educativos e memoráveis.

1.1 O Processo de Avaliação do Ambientes Pelos Indivíduos

A área de estudos da Psicologia Ambiental e das Relações Ambiente-Comportamento, no qual este estudo se baseia, concentra-se na investigação dos processos de interação entre as características físico-espaciais do ambiente e as respostas dos indivíduos que o utilizam. Para designar esses processos, é empregado o termo percepção ambiental. O processo de percepção ambiental como um todo, envolve várias etapas e experiências sequenciais, no qual duas se destacam: a percepção e a cognição. As experiências perceptivas são compreendidas como uma atividade sensório-motora. Referem-se à apreciação do mundo externo como estímulo presenciado no momento, algo imediatamente observado ou sentido através dos sentidos básicos. Ocorrem independentemente de operações internas como memória, reconhecimento e imaginação. Já as experiências cognitivas, são consideradas complementares à percepção, e entendidas como a maneira que o objeto percebido é codificado, armazenado e organizado na mente do observador de acordo com seus conhecimentos e valores acumulados. Segundo Weber (1995), a cognição 
é entendida como a etapa em que o que foi percebido adquire um valor para o indivíduo, tornando-se uma imagem significativa associada à memória e ao reconhecimento de algo e, assim, relacionada ao aprendizado.

O processo de percepção ambiental em jardins zoológicos segue um padrão definido: as pessoas entram em um novo ambiente, imediatamente o percebem e logo tentam dar sentido a ele, avaliando as suas características. O próximo passo é o desejo de transformar as informações em conhecimento (GAGNE 1985; GRAETZ, 1995). Entretanto, os estudos empíricos indicam que as pessoas podem ou não estar visitando o jardim zoológico com a intenção de aprender, e este entendimento é o primeiro passo para planejar a educação dos visitantes com sucesso.

O Modelo de Processamento de Informação desenvolvido por Gagne (1985) é considerado por vários autores como mais apropriado para o estudo do processo de aprendizagem (processo cognitivo) nos jardins zoológicos (EBENHÖH, 1995; PLOUTZ, 2012). A partir desse modelo, Falk $(2000,2006)$ desenvolveu uma nova teoria chamada Identidade do Visitante, que prognostica como as pessoas podem se comportar durante a visita. A teoria de Falk utiliza o conceito das affordances, desenvolvido por James Gibson (1986), devido a sua capacidade de mostrar a ligação entre o ambiente construído e o comportamento humano. Gibson, baseado na psicologia de Gestalt, reconheceu que o significado ou valor de um objeto é percebido imediatamente e que "cada coisa diz o que é [...] um fruto diz 'Me coma', a água diz 'beba-me' e trovão diz: 'Tema-me'". As Identidades identificam como as pessoas percebem as affordances que o jardim zoológico fornece, resultando assim, nas suas perspectivas quanto a visita (FALK, 2009).

Atualmente, os jardins zoológicos são vistos como locais propícios para estudos de percepção e cognição ambiental, comportamento, avaliação da paisagem, entre outros (GRAETZ, 1995). Neste estudo, utiliza-se a abordagem perceptiva e cognitiva para avalia o desempenho dos espaços abertos de jardins zoológicos a partir dos elementos morfológicos presentes nesses ambientes. Analisa- se a avaliação feita pelos indivíduos com a finalidade de entender quais atributos ambientais contribuíram para essa avaliação.

1.2 Elementos dos Espaços Abertos de Jardins Zoológicos

Ao longo do tempo os jardins zoológicos passaram por muitas mudanças, não apenas no sentido físico, mas também nos seus conceitos. Transcendendo de espaços simplórios, sem naturalidade, para verdadeiros parques de conservação da vida selvagem, com uma infraestrutura desenvolvida para o bem-estar tanto das espécies de animais que lá vivem, quanto para seus visitantes. A partir da década de 1970 a ecologia e a conservação da natureza se tornaram os princípios básicos para o planejamento dos jardins zoológicos, fazendo surgir um novo conceito chamado de imersão na paisagem. As estratégias de desenho e planejamento que apoiam este conceito têm como uma das principais intenções chegar ao lado emocional do público e só depois no seu lado intelectual, fazendo-o imergir tanto física como psicologicamente no espaço (COE, 2011). Atualmente o conceito de imersão na paisagem é denominado design imersivo (COE, 2012).

De acordo com essa linha de pensamento, o espaço neste estudo não é considerado somente sob o ponto de vista físico-espacial, mas também com relação aos indivíduos que com ele interagem. Tendo isso em consideração, e também que os jardins zoológicos são formados principalmente por espaços abertos, é essencial que ele seja planejado em sua totalidade para que o visitante se sinta envolvido no ambiente apresentado (EBENHÖH, 1992; COE, 2000; 2011; 2012; HANCOCKS, 2003). Segundo Jones et al., (1976), é indicado que o planejamento dos jardins zoológicos sejam realizados com a intenção de torna-los atrativos. As pessoas têm expectativas específicas quando os visitam. Alguns deles são conscientes, outros inconscientes, mas basicamente, o visitante deseja uma experiência agradável, divertida e educativa (EBE$\mathrm{NHÖH}, 1992)$. O desafio é criar um ambiente onde a aprendizagem seja divertida.

No planejamento dos espaços abertos dos jardins zoológicos, destacam-se sete categorias de elementos paisagísticos como influentes no desempenho do espaço: (1) estruturas e instalações 
de apoio aos visitantes; (2) elementos dos recintos/exposições; (3) naturalidade; (4) mobiliários; (5) recursos recreativos; (6) elementos de circulação; e, (7) dispositivos de orientação espacial (JONES et al., 1976; BITGOOD, 1988; EBENHÖH, 1992; GRAETZ, 1995).

De modo a tornar a visita ao jardim zoológico agradável, é necessário prover o espaço de estruturas e instalações de apoio aos visitantes. Tais estruturas são traduzidas em espaços como áreas de exposição, áreas de descanso, estacionamentos, restaurantes, áreas de piquenique, banheiros, quiosques de informação, lojas de lembrancinhas, edifício de educação ambiental e pracinhas. As áreas de exposição dos jardins zoológicos ocupam uma média de $60-70 \%$ do território. As estruturas classificadas como elementos físicos das exposições são as estruturas de malha (flexível ou rígida), fossos, corrimãos, vegetação e elementos de enriquecimento ambiental. A malha metálica é utilizada como uma barreira relativamente transparente entre o público e os animais (Figura 1a). Os fossos são escavações no terreno, com a presença ou não de água (Figura 1b), e tem como função a contenção dos animais, sem o visitante estar ciente disto.

A naturalidade é um dos fatores fundamentais nos jardins zoológicos e está relacionada a vegetação e a água. A vegetação pode auxiliar no aumento do uso dos espaços, principalmente se os arranjos da vegetação tiverem variedade e qualidade de textura, cor, massa, fluidez e efeitos olfativos. Os gramados podem determinar onde as pessoas podem se sentar, brincar e fazer piquenique ou apenas descansar e tomar banho de sol, e assim, influenciar o uso do espaço. As árvores oferecem sombra e podem servir como elemento recreacional para as crianças. A água está entre os aspectos que os visitantes mais gostam nos jardins zoológicos, e pode ser usada em uma ampla variedade de combinações. Pode ser encontrada em forma de lagos e fontes de água ou como fontes incomuns com esculturas divertidas. Além das qualidades estéticas de corpos d'água, há uma possibilidade de exibir alguns tipos de animais que podem ser atrativos.

De modo a tornar a visita ao jardim zoológico agradável, é necessário prover o espaço de mobiliários. Os mais frequentemente

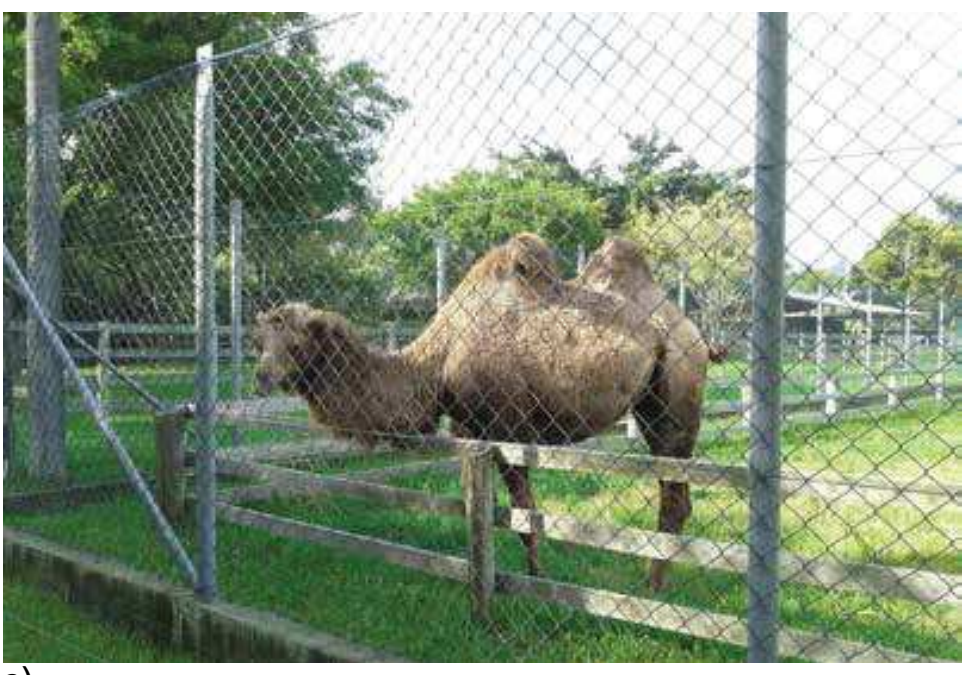

a)

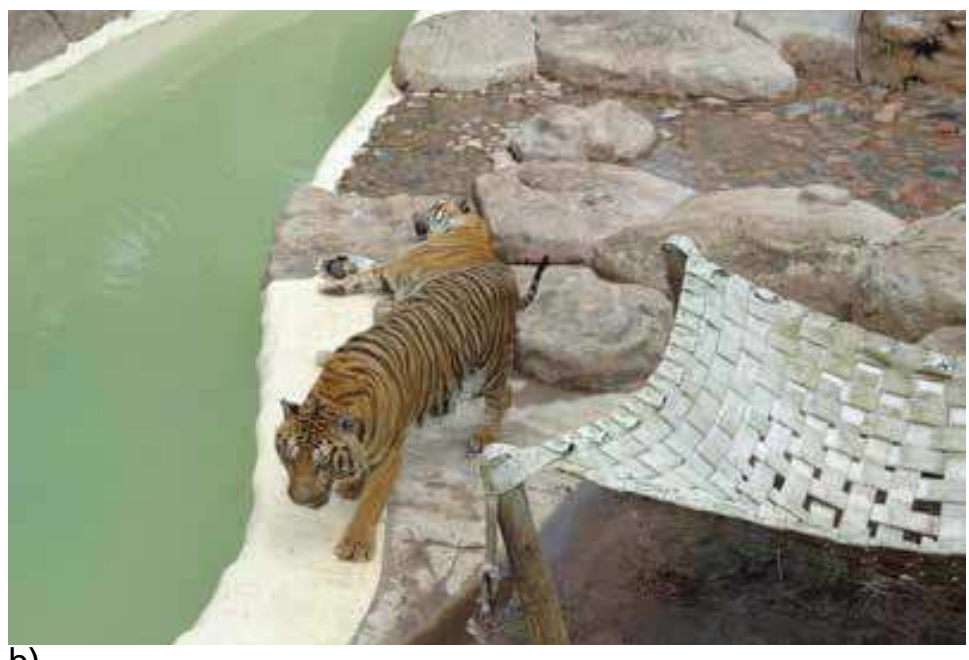

b)

Figura 1: Barreiras em recintos de jardins zoológicos: a) recinto com barreira de tela metálica; b) recinto com barreira de fosso com água. Fonte: fotos das autoras, 2014 

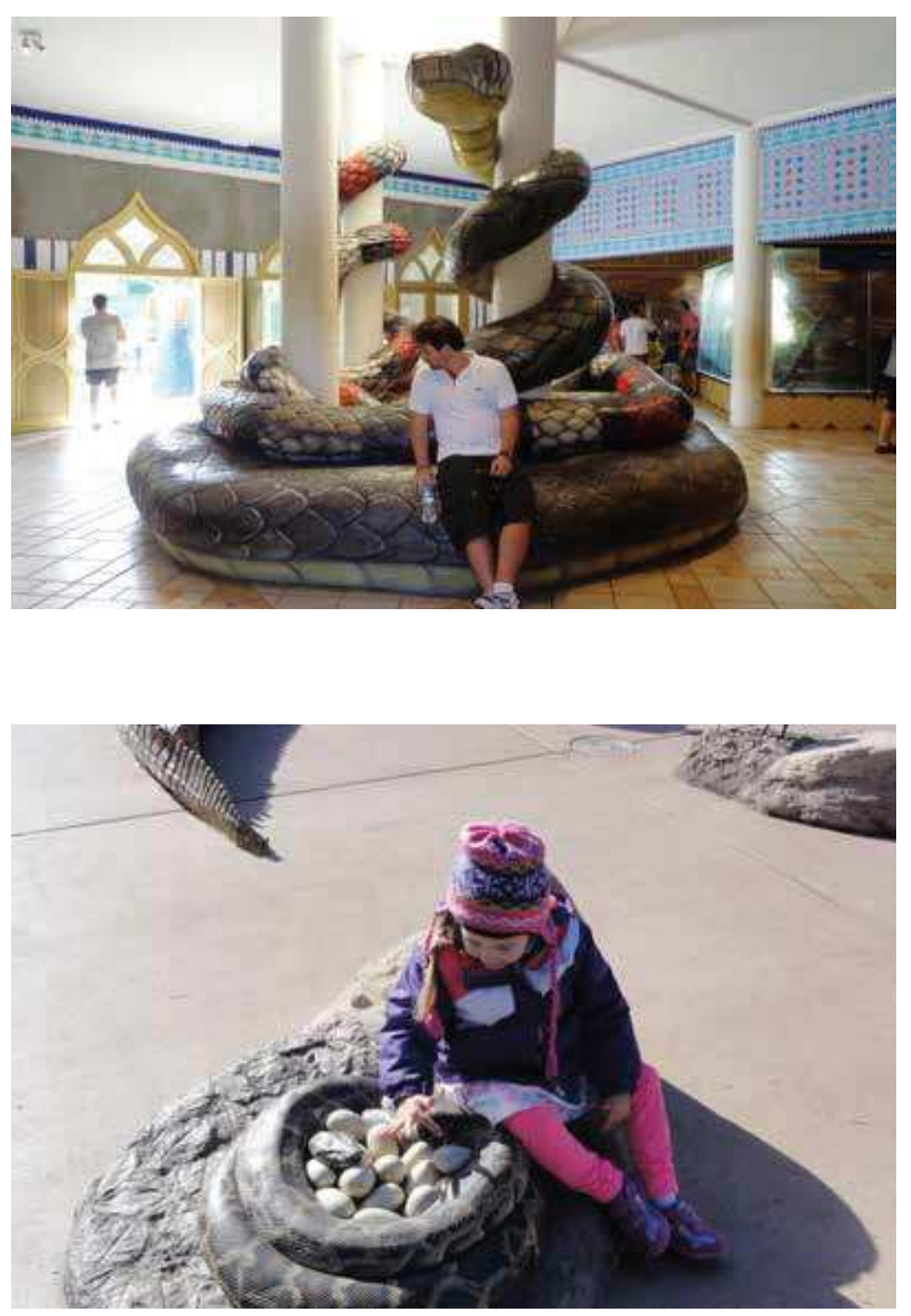

Figura 2: Esculturas de animais como recursos recreativos em jardins zoológicos. Fonte: fotos das autoras, 2014 encontrados nos jardins zoológicos são bancos, lixeiras, luminárias e bebedouros. Esses mobiliários podem ser simples ou com alguma temática que contribui com a educação ambiental dos visitantes.

Os recursos recreativos são dispositivos de entretenimento e aprendizagem que oferecem a possibilidade de interação. Consistem em dispositivos passivos ou ativos que envolvem um ou mais sentidos e sempre fazem com que o visitante atue ou reaja. Os recursos recreativos que podem ser encontrados em jardins zoológicos são painéis e pinturas, elementos e jogos de entretenimento educacional, esculturas (Figura 2) e também pracinhas para crianças. As pracinhas podem ser concebidas como simples, coloridas ou com alguma temática.

A circulação pode ser pensada conforme os efeitos sensoriais que se deseja obter no espaço e das linhas de visadas que se pretende proporcionar aos visitantes. Podem criar variados efeitos, tais como mistério e surpresa. A clareza visual também pode influenciar na facilidade de locomoção e no direcionamento de visual. Quanto maior a visibilidade de um objeto ou espaço, mais atenção ele poderá receber. Aspectos como largura dos caminhos, tipo de pavimentação, acessibilidade, necessidade de implantação de pontes, escadas e observatórios devem ser considerados. Os dispositivos de orientação espacial também são importantes nesses ambientes, pois permitem que as pessoas se localizem. Quando as pessoas ficam perdidas, não absorvem todas as informações educativas e recreativas fornecidas pelo espaço. Os dispositivos de orientação espacial mais comuns nos jardins zoológicos são sinais direcionais, os de identificação e os educacionais, mapas de você-está-aqui e mapas de mão.

\section{Metodologia Utilizada}

Foi considerada como estratégia fundamental mais adequada a do estudo de caso (YIN, 2001). Como objeto de estudo, foi selecionado o Parque Zoológico da Fundação Zoobotânica do Rio Grande do Sul (FZB/RS), localizado em Sapucaia do Sul, no Estado do Rio Grande do Sul, Brasil, com área de visitação de 50 hectares 
(Figura 3). Os critérios utilizados para a seleção do objeto de estudo foram: a) localização: o objeto de estudo deveria ser localizado no Estado do Rio Grande do Sul para facilidade da pesquisa; ser um jardim zoológico do meio urbano; b) características: ser caracterizado como um jardim zoológico contemporâneo; oferecer programas de educação ambiental; possuir uma grande área de visitação e plantel variado; possuir grande fluxo de visitantes; e c) disponibilidade: interesse dos jardins zoológicos em participar do estudo.

O estudo conta com quatro métodos de levantamento de dados: (1) levantamento físico, onde foram feitas medições físicas e registro fotográfico das características formais e elementos físicos do design presentes no espaço aberto do jardim zoológico para complementar os dados disponíveis previamente; (2) observação comportamental, onde foi identificado o uso do espaço; (3) questionário e (4) entrevista, no qual foram identificados dados de satisfação e preferência dos visitantes. A amostra de pessoas que responderam o questionário e participaram da entrevista referese aos visitantes do jardim zoológico, e caracteriza-se como uma amostra de oportunidade, composta por pessoas que estavam dispostas a participar do estudo (Tabela 1).

No levantamento físico, foram evidenciadas as características físicas do Parque Zoológico da FZB/RS e produzido o Mapa Geral do espaço. O Parque Zoológico foi caracterizado de acordo com os elementos físicos do design de jardins zoológicos.

Quanto as estruturas e instalações de apoio aos visitantes, o ambiente físico, aberto ao público, conta com bilheteria, estacionamento, um restaurante (Figura 4a), quiosques de informações e de comercialização de alimentos, sanitários, centro de educação ambiental, áreas de descanso e piquenique. Apresenta variados tipos de recintos/exposições, inclusive alguns de grades de ferro, ainda da década de 1960. As barreiras mais comuns são os de malha metálica (Figura 4b), mas fossos secos e com água também
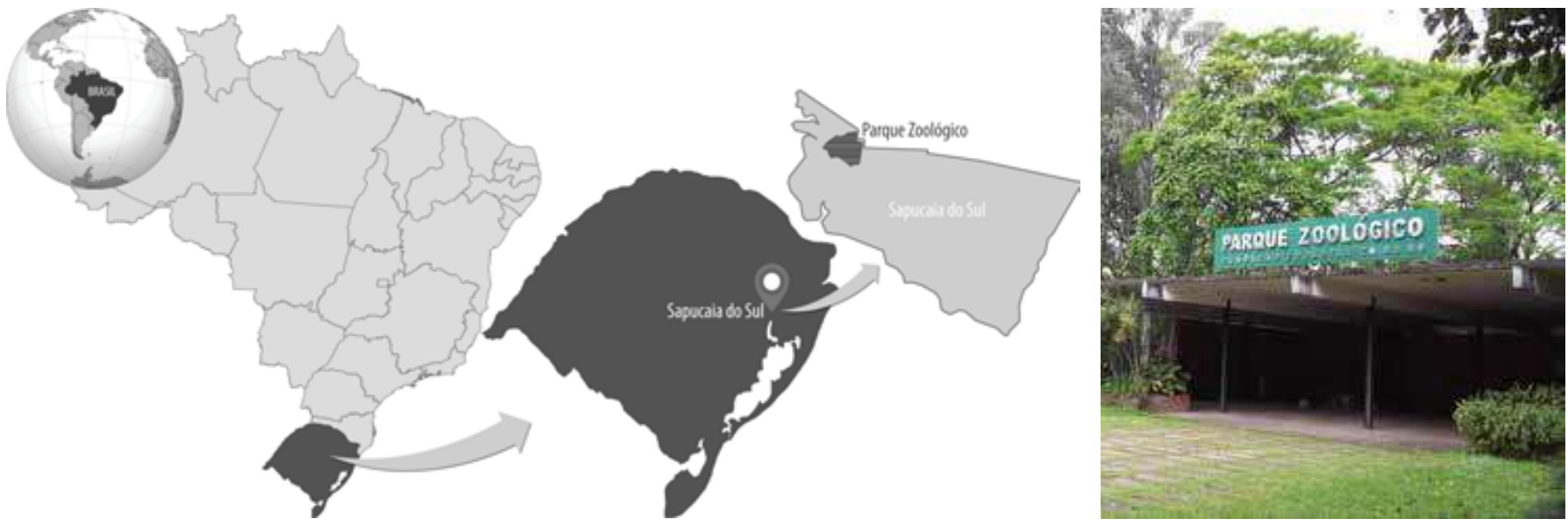

Figura 3: Localização do Parque Zoológico da FZB/RS. Fonte: das autoras - adaptado do Google Earth, 2017. 
Tabela 1: Amostra de participantes em cada método de coleta de dados.

\begin{tabular}{l|c|c|c|c|c|c|c}
\hline \multirow{2}{*}{ MÉTODO } & \multicolumn{3}{|c|}{ GÊNERO } & \multicolumn{3}{c}{ FAIXA-ETÁRIA } & \multirow{2}{*}{ TOTAL } \\
\cline { 2 - 9 } & Feminino & Masculino & Criança & Adolescente & Adulto & Idoso & \\
\hline Observação comportamental & 3671 & 3444 & 1767 & 707 & 4237 & 404 & 7115 \\
\hline Questionário & 48 & 48 & - & 3 & 93 & - & 96 \\
\hline Entrevista & 12 & 13 & - & - & 15 & 10 & 25 \\
\hline \multicolumn{3}{l|}{ TOTAL DE PARTICIPANTES } \\
\hline
\end{tabular}

Fonte: das autoras, 2017.

podem ser encontrados (Figura 4c). Elementos de enriquecimento ambiental para os animais também estão presentes em todos os recintos.

Em relação a vegetação e recursos naturais, o espaço é caracterizado pela presença de muita vegetação nativa, trilhas e locais totalmente preservados. A vegetação ornamental se faz presente em grande parte das áreas (Figura 4d). Há um grande lago em destaque (Figura 4e), além dos lagos dentro dos recintos de animais. Mobiliários como bancos e lixeiras são comuns e bem distribuídos. Há grande variedade de design desses elementos, o que demonstra que foram implantados no ambiente em diferentes tempos. Como recurso recreativo há uma praça infantil e um trenzinho para fotos (Figura 4f).

Quanto aos elementos de circulação, encontram-se variados tipos de caminhos, com diferentes tipos de pavimentação, mas a maior parte é de terra batida (Figura 4g). Faltam demarcações limites na área dos recintos e sinalização, pois alguns caminhos levam o visitante para as trilhas ou a saída. Muitos caminhos não possuem acessibilidade. Pontes, escadarias e trapiches (Figura 4h) são elementos presentes. Dispositivos de orientação espacial como sinalização direcional e mapas você-está-aqui (Figura 4i) são encontrados em vários pontos do jardim zoológico. Sinalizações educativas estão presentes em todos os recintos.
Para a análise do espaço físico, a área de visitação do Parque Zoológico foi dividida em 11 áreas menores: 01 - Fazenda, 02 - Rinoceronte, 03 - Macacos, 04 - Pássaros, 05 - Carnívoros, 06 Camelos, 07 - Estacionamento, 08 - Piquenique, 09 - Pracinha, 10 - Lago e 11 - Alimentação (Figura 5). A delimitação das áreas foi definida de acordo com as características das mesmas.

A observação comportamental foi realizada com a técnica de registro dos mapas comportamentais no Parque Zoológico, nos dias 29 e 30 de abril, e no dia 2 de maio de 2017, em cada turno do dia (manhã e tarde). Para uma maior padronização, as observações foram realizadas a partir de quatro trajetos pré-estabelecidos. A técnica de aplicação dos métodos avaliativos (questionário e entrevista) foi a feita pessoalmente e individualmente, no próprio local de estudo. O questionário foi aplicado nos dias 14 e 15 de outubro de 2017. Seu conteúdo incluiu perguntas sobre satisfação, preferência entre as áreas de exposição e animal favorito, além de outras questões sobre elementos de design, configurações de caminhos e aspectos de naturalidade. A entrevista foi aplicada nos dias 24 e 25 de fevereiro de 2018 e seu conteúdo referiu-se a aspectos de aprofundamento dos dados levantados pelo questionário. 


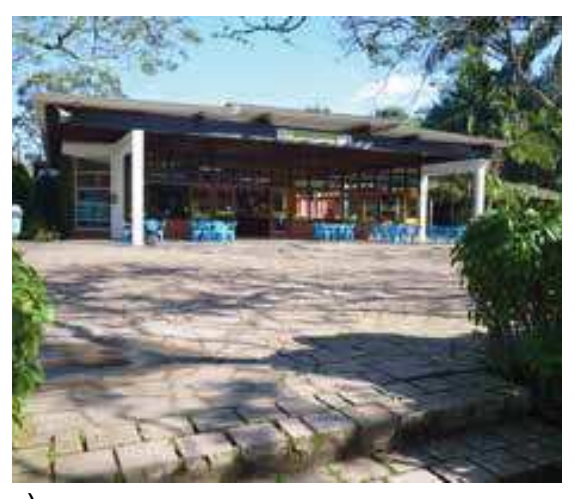

a)

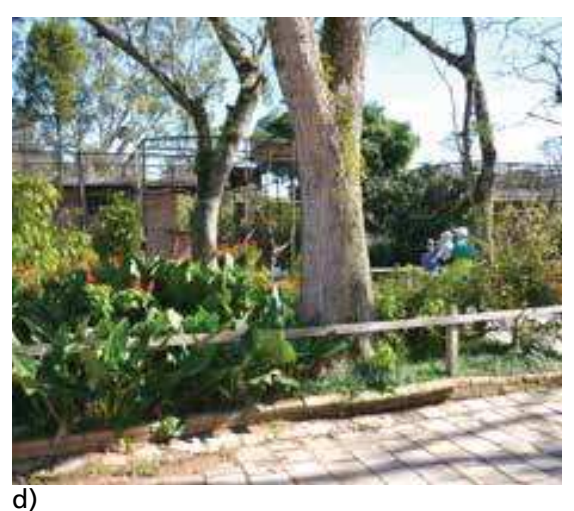

124

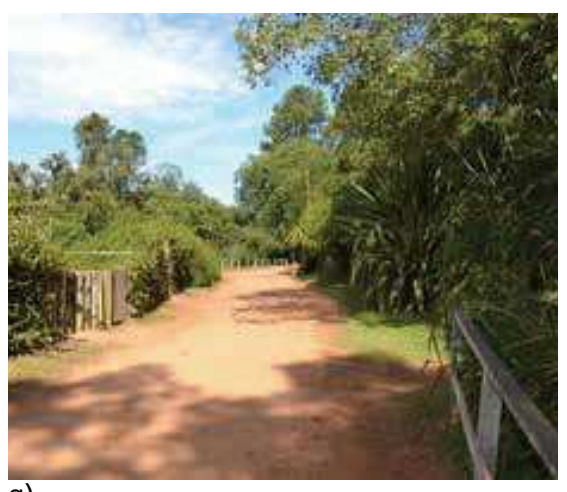

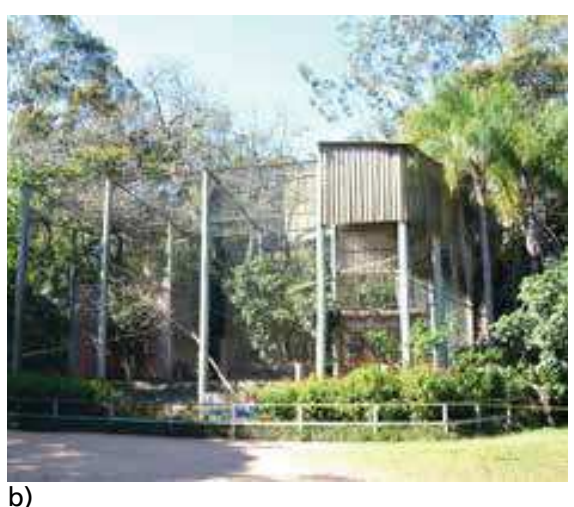
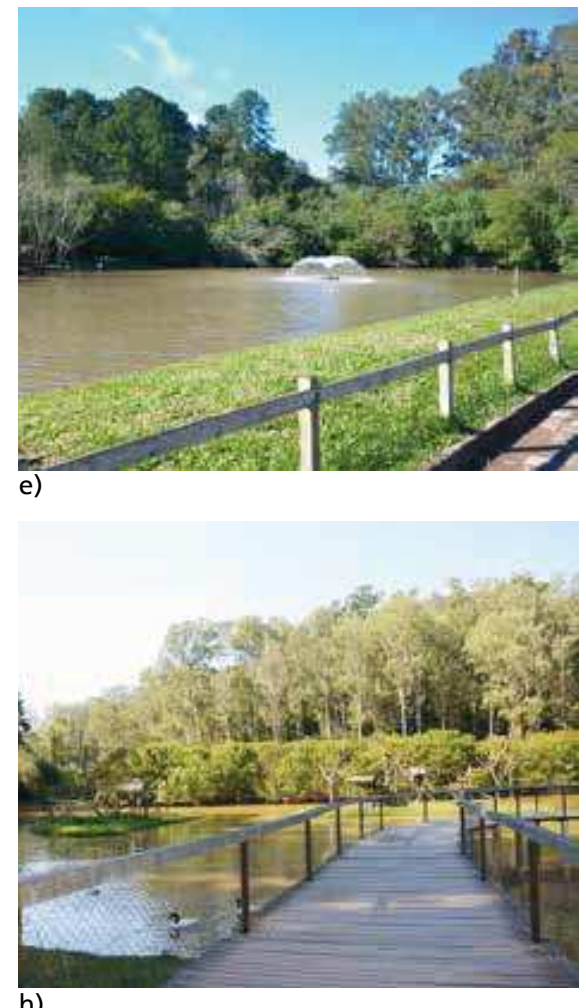
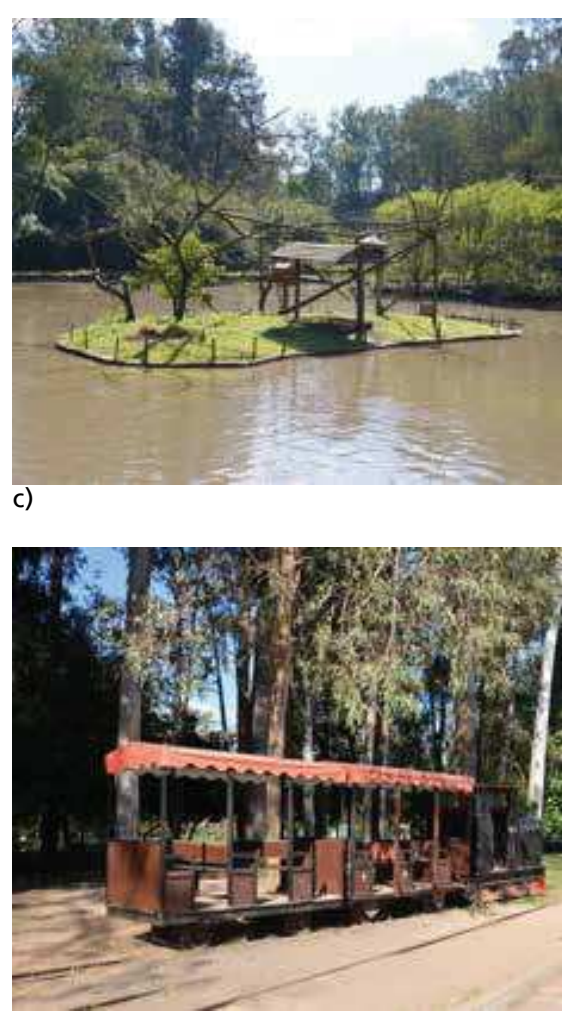

.

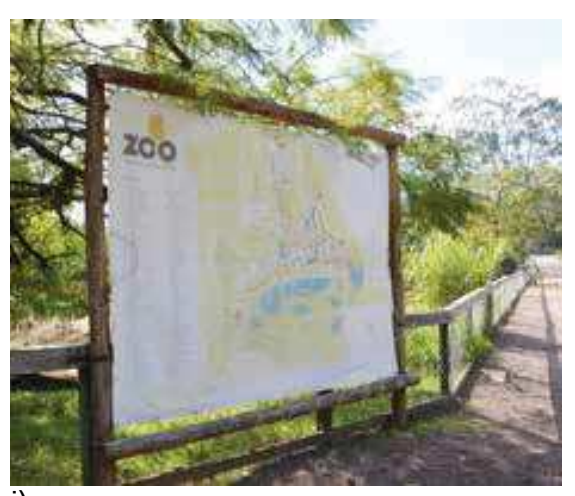

Figura 4: Conhecendo a o Parque Zoológico: a) restaurante; b) recintos de malha metálica; c) recinto com lago; d) vegetação ornamental; e) lago; f) trenzinho;

g) caminhos de terra batida; h) trapiche do lago; i) mapa você-está-aqui. 


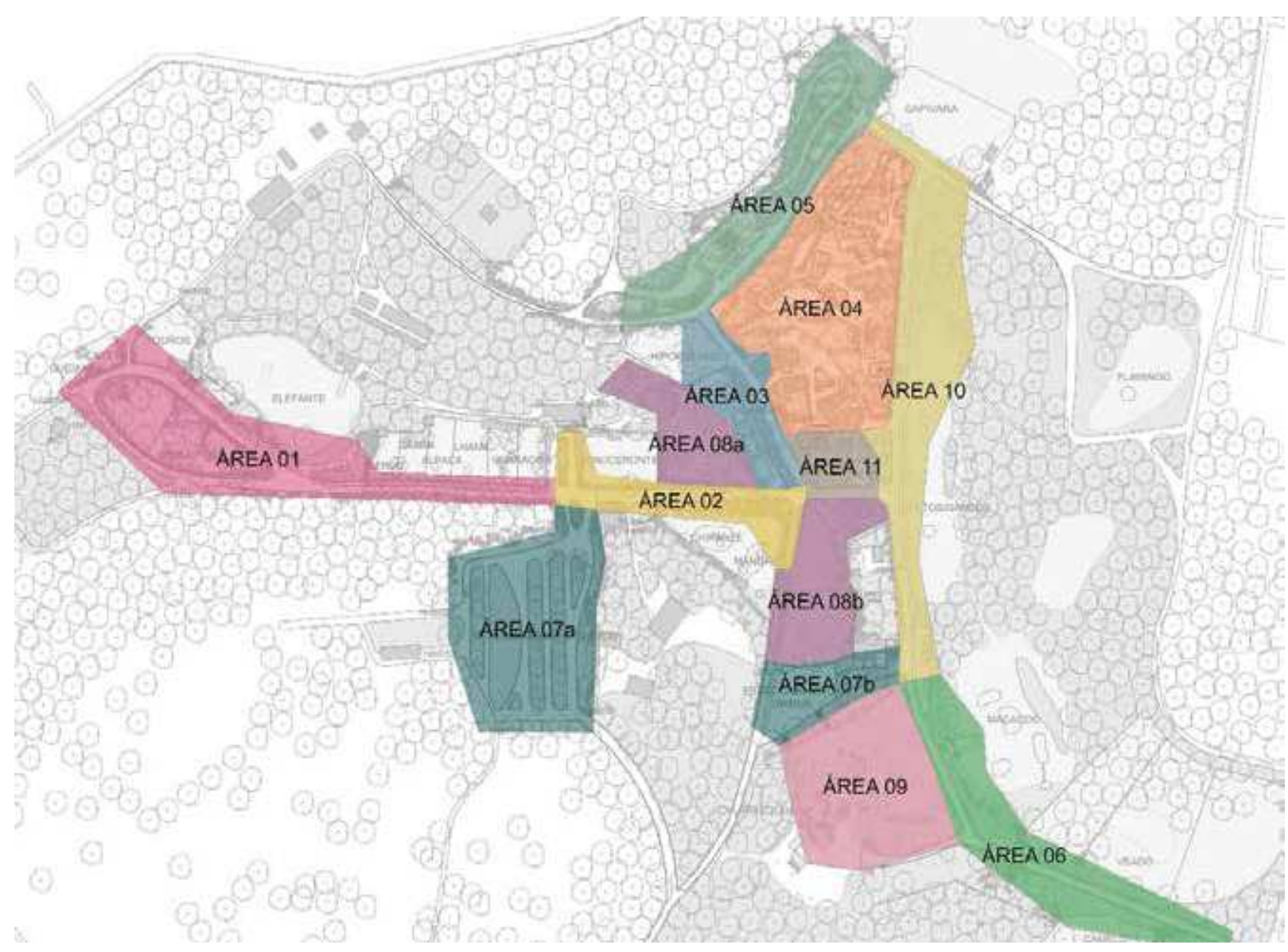

Figura 5: Divisão da área de visitação do Parque Zoológico em àreas de análise.

\section{Resultados}

Os dados levantados nos seis mapas comportamentais (correspondentes aos dias e turnos de observação) foram digitalizados e sobrepostos, formando um mapa síntese de uso (Figura 6).

Constatou-se, a partir das observações comportamentais, que as Área 03 - Macacos é a mais frequentada e Área 06 - Camelos é a menos frequentada pelos visitantes.

A Área 03 - Macacos ocupa posição central no Parque Zoológico e tem $1.822,23 \mathrm{~m}^{2}$ de área passível de acesso e visitação. A maior parte das exposições presentes são recintos de macacos: bugios, babuíno-sagrado, macaco aranha, sagui, mico-leão-dourado e macaco-da-noite. As outras duas exposições referem-se aos recintos dos hipopótamos e dos furões. O recinto dos hipopótamos possui barreira de cerca metálica, e fica em um nível mais baixo dos visitantes. Os demais são grandes gaiolas de malha metálica, que compõem uma unidade sequenciada. É caracterizada por grandes árvores, que formam um emolduramento do caminho e pela presença de grande quantidade e variedade de vegetação ornamental. A vegetação ornamental está presente em pra- 


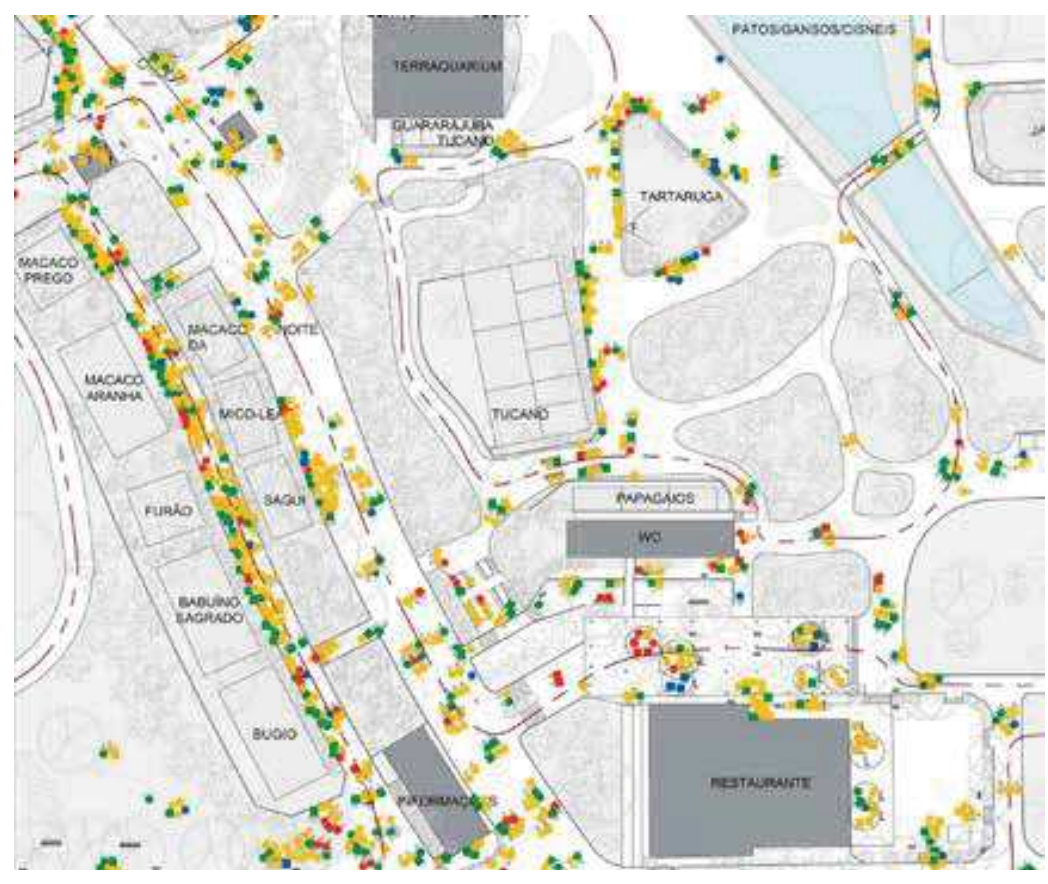

126

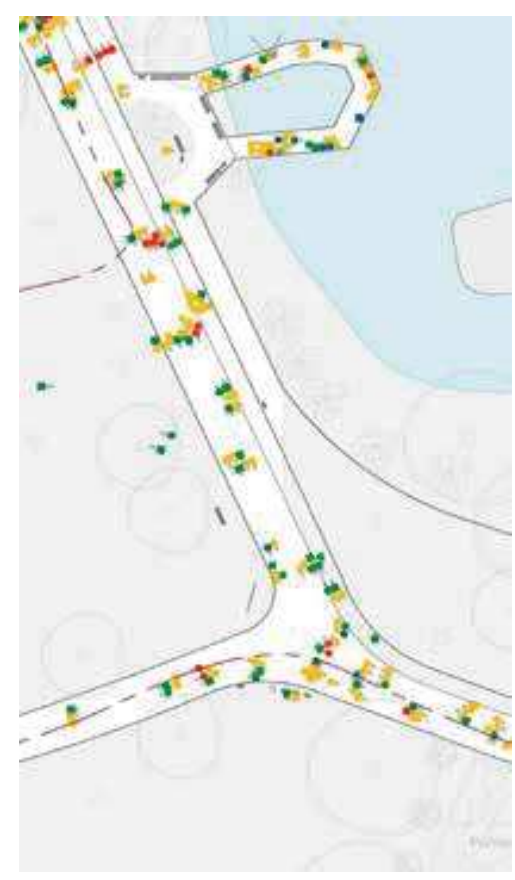

b)
Figura 6: Recortes de exemplo do mapa síntese de uso: a) recorte mostrando partes das Áreas 03 - Macacos e 04 - Pássaros (parte - Macacos e 04 - Pássaros (parte mostrando parte da Área 06 Camelos.

Fonte: das autoras, 2017 ticamente em todo o espaço, e no canteiro central, que divide os dois caminhos da área, esta vegetação é mais intensa. Estão disponíveis um quiosque de informações, dois quiosques de alimentação, quatro bancos e três lixeiras. Também há um pergolado coberto de plantas trepadeiras. Os caminhos são estreitos e retos, pavimentados com paralelepípedos de pedra e totalmente envoltos por vegetação, sem possibilidade de visualizar os espaços fora da área. Há poucos sinais direcionais, mas há um mapa você-está-aqui. A sensação do espaço é de compacidade e envolvimento, proporcionadas pelas linhas de visão fechadas. Área com alta riqueza visual.

Verificou-se na Área 03, grandes quantidades de visitantes em atividade estática em variados pontos do espaço, assim como, uma quantidade considerável de pessoas transitando no caminho mais estreito, onde encontram-se as exposições de macacos de grande porte. Percebe-se que as pessoas em fluxo não estão apenas utilizando o espaço como passagem. Elas se movimentam para observar a próxima exposição, para apreciar a paisagem e a vegetação ornamental ou para seguir observando o topo das grandes árvores onde frequentemente há pássaros cantando. Todas as exposições da área recebem atenção dos visitantes e nelas estão os pontos de maior intensidade de uso. Os bancos localizados no quiosque de alimentação, permanecem ocupados com frequência.

A Área 06 - Camelos localiza-se na periferia leste do Parque Zoológico e tem $10.338,40 \mathrm{~m}^{2}$ de área passível de acesso e visitação. Há cinco exposições: aves aquáticas (gansos, cisnes, patos e marrecos) juntamente com os chipanzés, que ficam em uma ilha no meio do lago, camelos, cervos e veados. As exposições são grandes e muito distantes uma das outras. No recinto dos camelos 
a barreira é de cerca de madeira, nos dos cervos e veados é de cerca de malha metálica. A área é caracterizada pela presença de grandes árvores nativas, de um pomar, localizado em frente ao recinto dos veados e pela inexistência de vegetação ornamental. Há um trapiche no lago dos macacos e um trenzinho recreativo. Não há banheiros ou quiosques de alimentação. A água se faz presente nos recintos dos macacos e das aves aquáticas. Há oito bancos e seis lixeiras. Os caminhos são retos e pavimentados com uma ciclo-faixa asfaltada em toda extensão. Há poucos sinais direcionais e apenas um mapa você-está-aqui. O espaço passa sensação de amplitude e monotonia. Há poucos elementos e baixa riqueza visual.

Verificou-se na Área 06, poucas pessoas visitando o espaço, e a maior parte delas está em atividade de fluxo, o que demonstra que o espaço é usado majoritariamente como passagem. Pessoas paradas observando animais ou em outra atividade não motora são escassas. Os visitantes em atividade estática se concentram principalmente no trapiche do lago onde ficam os recintos dos macacos e no trenzinho, que é utilizado como meio recreativo por crianças e onde são tiradas fotos em família. Percebe-se tam- bém o uso dos bancos localizados na lateral do recinto de camelos e de uma pequena concentração de pessoas observando os camelos.

\subsection{Preferência por Área de Visitação}

Considerando os resultados obtidos por meio dos questionários, afirma-se que os visitantes do jardim zoológico em estudo estão muito satisfeitos ou satisfeitos $(84,4 \%)$ com os espaços abertos. Destacaram-se as mesmas áreas mais e menos frequentadas como as áreas mais e menos preferidas. Como preferida destacou-se a Área 03 - Macacos, com 39,6\% de indicação (Tabela 2). Nesta área estão os animais citados como favoritos por apenas $17,6 \%$ dos visitantes (Tabela 3). Esses dados indicam que a presença do animal favorito não interferiu na preferência dos visitantes, mas sim, que as configurações da área contribuíram para a escolha. Com destaque negativo foram evidenciadas as Áreas 02 -Rinoceronte e 06 - Camelos, indicados com menor frequência pelos visitantes com $1 \%$ e $8,3 \%$ respectivamente. Nestas áreas estão os animais citados como preferidos de $15,6 \%$ (Área 02) e 13,5\% (Área 06) dos visitantes.

Tabela 2: Compilação das Respostas da Pergunta Sobre a Preferência Entre as Áreas de Exposição.

\begin{tabular}{|c|c|c|c|c|c|c|c|c|c|c|c|}
\hline ÁREA & FREQUÊNCIA & \multicolumn{10}{|c|}{ GRÁFICO } \\
\hline (1) ZEBRAS (fazenda) & $18(18,8 \%)$ & \multirow{7}{*}{$\begin{array}{r}\text { zebras } \\
\text { rinocerontes } \\
\text { macacos } \\
\text { pássaros } \\
\text { carnivoros } \\
\text { camelos }\end{array}$} & & & & & & & & & \\
\hline (2) RINOCERONTES & $1(1,0 \%)$ & & & & & & & & & & \\
\hline (3) MACACOS & $38(39,6 \%)$ & & 1 & & & & & & & & \\
\hline (4) PÁSSAROS & $22(22,9 \%)$ & & & & & & & & & & \\
\hline (5) CARNÍVOROS & $9(9,4 \%)$ & & & & & & & & & & \\
\hline (6) CAMELOS & $8(8,3 \%)$ & & & 5 & 10 & 15 & 20 & 25 & 30 & 35 & 40 \\
\hline TOTAL & $96(100 \%)$ & & & & & & & & & & \\
\hline
\end{tabular}

Fonte: das autoras, 2017 
Tabela 3: Compilação das Respostas da Pergunta Sobre o Animal Favorito dos Visitantes.

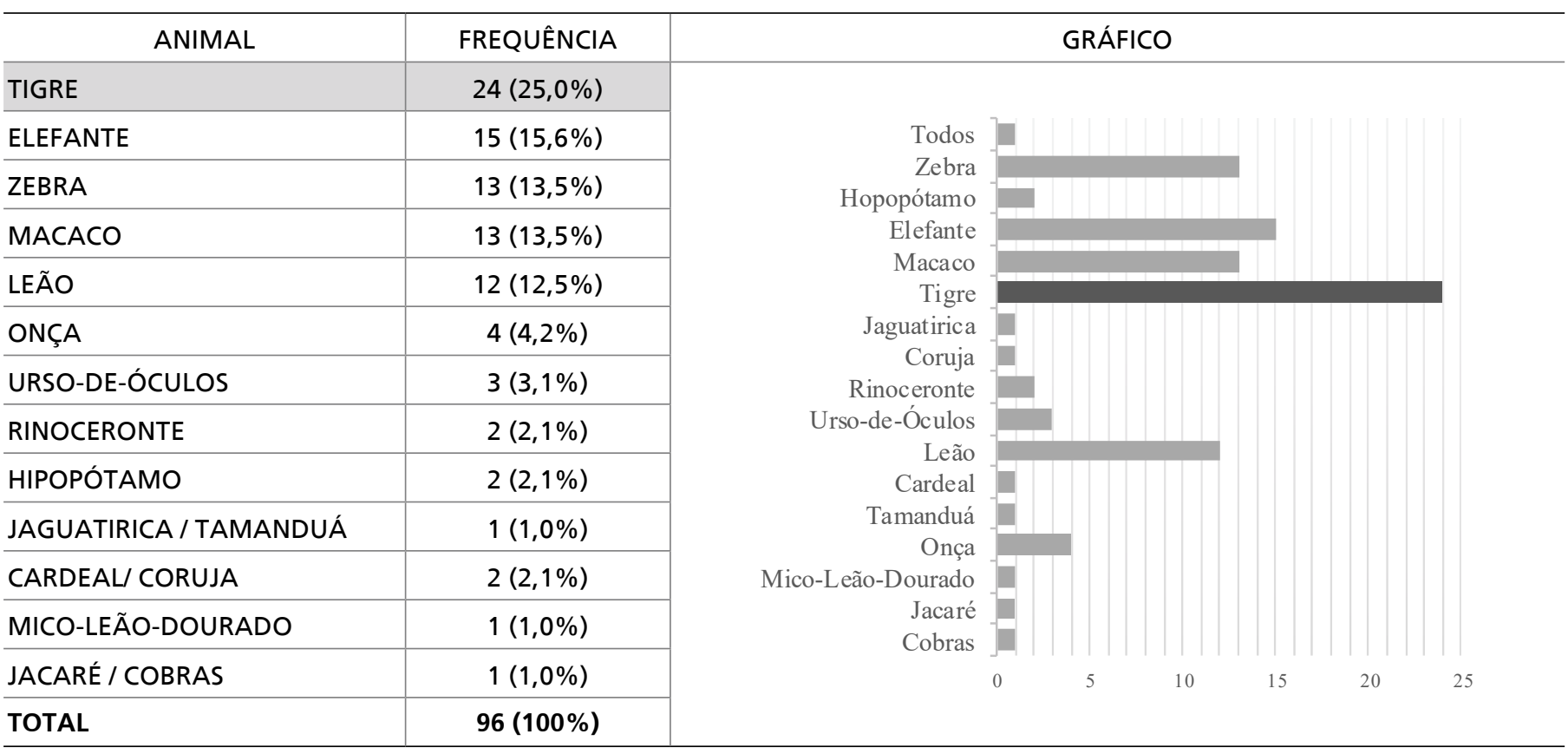

Fonte: das autoras, 2017.

Nas entrevistas foram levantados dados referentes as características que tornam as áreas mais e menos preferidas, no caso, a Área 03 - Macacos e a Área 06 - Camelos. Foi utilizada no estudo a Área 06 - Camelos e não a Área 02 - Rinocerontes pois apesar dela ser a segunda menos preferida, e não a primeira, é a área de menor atividade de visitantes.

Foi identificado que o principal aspecto que a torna a Área 03 - Macacos mais preferida é a diversidade de animais. Essa área oferece a possibilidade de se observar uma maior quantidade de animais com um menor tempo pois é composta principalmente por recintos de grandes gaiolas de malha metálica posicionadas uma ao lado da outra, formando uma unidade sequenciada (Figura 7a), e isso permite que vários animais sejam colocados próximos. As barreiras de malha metálica também possibilitam que haja uma maior proximidade entre os animais e os visitantes, e assim, seja possível a sua melhor visualização. Ambas, proximidade e visualização dos animais, são apontadas pelos visitantes como aspectos que a tornam a área mais preferida.

É citada também a questão da organização do espaço, que está relacionada ao seu planejamento (entendido como ordem) e sua manutenção como aspectos que a tornam a área mais preferida. Verifica-se uma relação entre a organização do espaço com a 
preferência dos mesmos. A uniformização do espaço e dos seus elementos físicos e caminhos pavimentados que demonstram um maior planejamento voltado à necessidade dos visitantes, são fatores de influência na preferência dessa área. A riqueza visual e a vegetação também são aspectos fortemente apontados como contribuintes para a preferência pela área. A Área 03 - Macacos é um espaço compacto, com quantidade de estímulos muito mais elevada que as demais áreas do Parque Zoológico e que passa sensação de envolvimento pelas suas linhas de visão fechadas. Também é caracterizada por grandes árvores (Figura 7b) (que formam um emolduramento do caminho e proporcionam escala vertical, intimidade e aconchego), pela presença de variedade de vegetação ornamental e por um pergolado de plantas trepadeiras. As grandes árvores se mostraram um elemento de importância nessa área, pois além de contribuírem na riqueza visual por seus formatos variados e texturas de folhas, também proporcio-

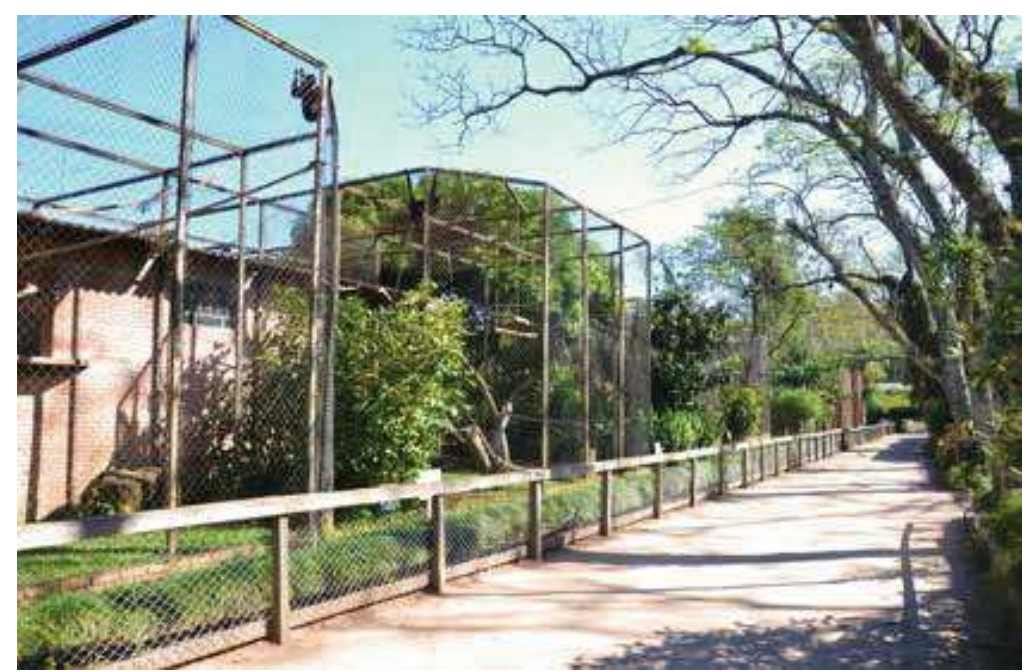

a)

Figura 7: Área 03 - Macacos, mais preferida: a) unidade sequenciada de gaiolas; b) caminhos pavimentados e com vegetação ornamental e envolvente. Fonte: fotos das autoras, 2016 nam sombra, criando conforto térmico adequado. E isso torna o espaço onde localizam-se os bancos e os quiosques de alimentação agradáveis para as pessoas descansarem.

É interessante destacar a relação existente entre a área favorita e preferência por tipos de barreiras entre pessoas e animais. No contexto geral do parque, entre todos os tipos de barreiras citadas, os visitantes mostraram preferência pelas de tela metálica $(29,2 \%)$, típicas das grandes gaiolas. Este é o tipo de barreira de $86,7 \%$ dos recintos da área favorita, Área 03 - Macacos. Por meio das entrevistas percebeu-se isso se deve pela visibilidade e proximidade com os animais já expostas anteriormente. Estar mais perto dos animais é importante para os visitantes, e esse tipo de barreira permite essa proximidade, proporcionando uma relação mais intimista (Figura 8).

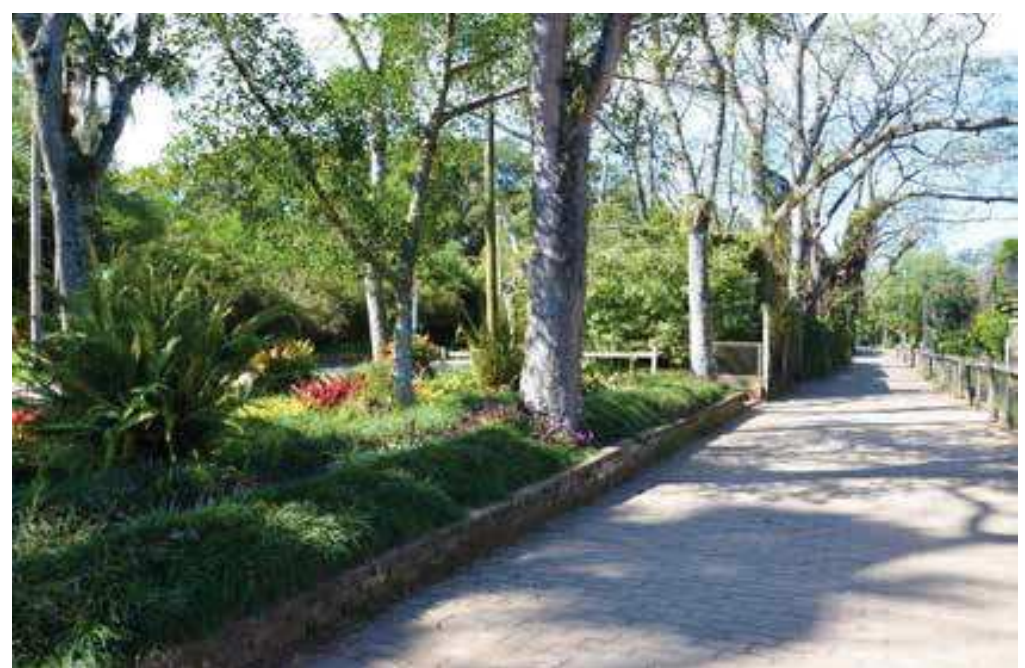




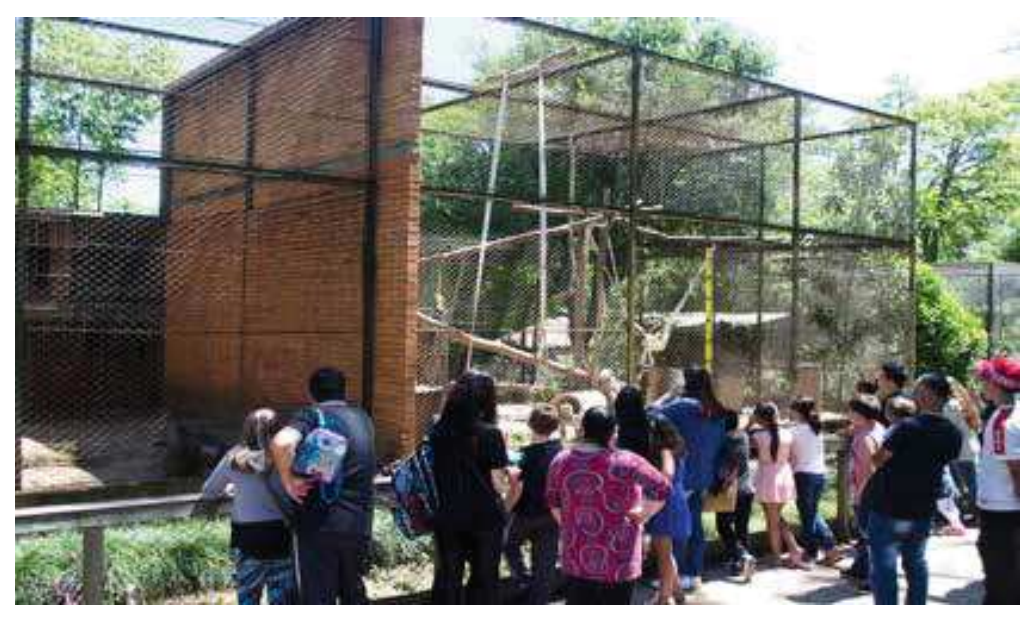

Figura 8: Visitantes em recintos de tela metálica da Área 03 - Macacos. Fonte: fotos das autoras, 2016

Quanto a Área 06 - Camelos, foi identificado que o principal aspecto que a torna menos preferida pelos visitantes é a distância a ser percorrida. Essa área fica na extremidade leste do Parque Zoológico, longe do estacionamento e das demais áreas de exposição, o que faz com que o visitante tenha que caminhar muito até chegar a ela. A área também não tem possibilidades de percursos diferentes para ida e volta (circuitos alternativos interligados), visto que é composta apenas por uma via, e assim, os visitantes tem que passar pelas mesmas exposições duas vezes.

A ausência de estímulos visuais no espaço e falta de atividades também é apontada como um aspecto negativo. São citados pelos visitantes como aspectos influentes na não preferência pela área a pouca diversidade de animais e a pobreza visual do ambiente. Os visitantes relatam que devido a todos esses aspectos a área se torna desinteressante e monótona, e assim, perdem a vontade de ir e estar nessa área (Figura 9). Não há vegetação ornamental ou design divertido e bancos são escassas. Assim, a

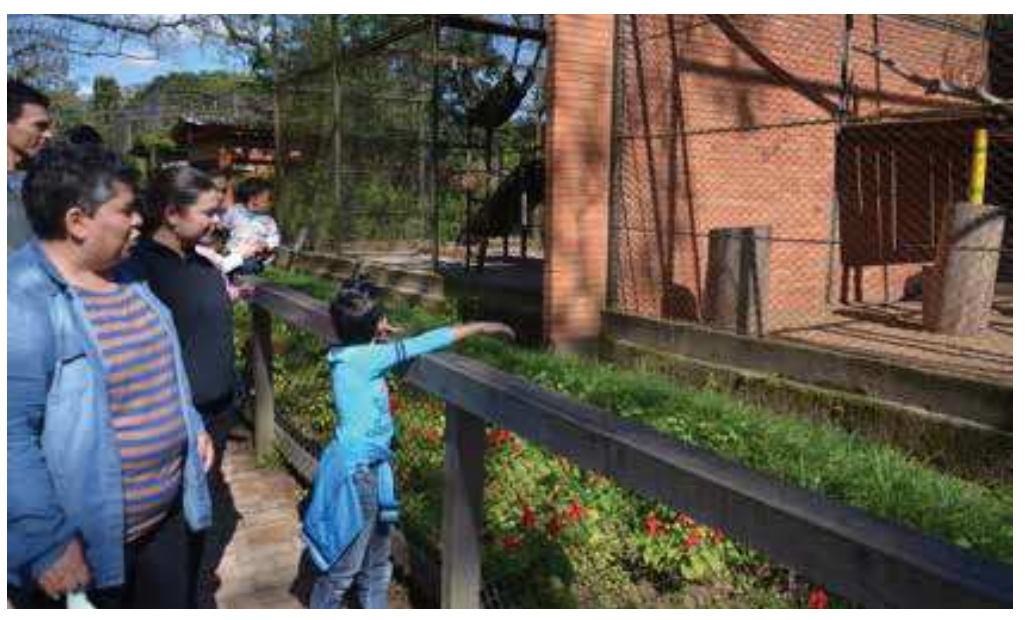
que causa a baixa preferência.

$$
\begin{aligned}
& 3.2 \text { InfluênCIa da Naturalidade e dos Caminhos } \\
& \text { No Uso do Espaço }
\end{aligned}
$$

Por meio dos mapas comportamentais pôde-se verificar um intenso uso em praticamente todas as áreas do Parque Zoológico. No entanto, foi constatado também uma maior diferenciação do número de indivíduos nos locais (dentro das áreas citadas) de acordo com a presença de naturalidade e com as configurações dos caminhos.

Quanto a presença de naturalidade (vegetação e fontes de água), verificou-se que as áreas próximas a água se mostraram muito atraentes para o público, ainda que alguns não possuam exposições de animais. Mesmos nas áreas menos preferidas há concentração de pessoas ao longo dos lagos. E eles são os locais onde encontra-se a maior parte das atividades de fotografar di- 

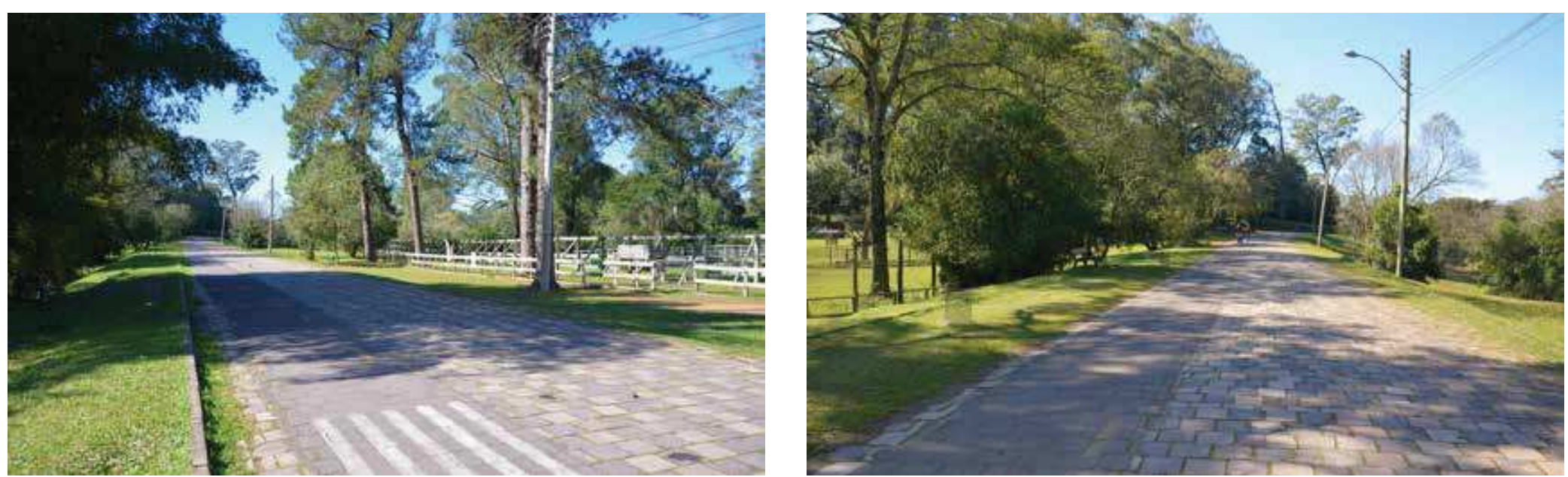

Figura 9: Área 06 - Camelos, menos preferida: pobreza visual e pouca diversidade. Fonte: fotos das autoras, 2016

recionada a outros visitantes (membros do grupo) e não a animais. Este acontecimento também é constatado nos recintos. Os recintos que contém água são atrativos para os visitantes, sendo os pontos de maior densidade de pessoas nas áreas de exposição em que estão localizados.

Em relação a vegetação, verifica-se que ela possui grande influência na intensidade de uso, contribuindo para a permanência das pessoas no espaço. Afirma-se, a partir dos dados levantados, que a vegetação envolvente e ornamental seja a preferida dos visitantes não somente por sua aparência, mas devido a sensação de planejamento que ela passa ao espaço, ou seja, que aquela vegetação está ali cumprindo um proposito anteriormente definido e não que esteja colocada ali por acaso. $O$ cuidado com os espaços é considerado um fator de influência na preferência por áreas e no uso das mesmas. A vegetação ornamental, que chama atenção dos visitantes e que possui boa aparência, e as grandes árvores que proporcionam sombra e um ambiente agradável em dias quentes, proporcionam a sensação de agradabilidade incentivam a permanência das pessoas nos espaços. Estes dados são confirmados nas entrevistas, onde foram apontados como aspectos que os visitantes mais gostaram a naturalidade do ambiente, seguido pela sombra e o lago, proporcionados pela própria naturalidade. Destaca-se que a naturalidade recebe mais valor positivo do que os animais propriamente ditos.

Quanto as configurações dos caminhos, algumas considerações podem ser feitas sobre preferências quanto a sua largura e comprimento. Quanto a largura, a Área 03 - Macacos possui caminhos estreitos e uma alta densidade de visitantes, formando aglomerações, ainda assim é considerada a área preferida dos visitantes. A Área 04 - Pássaros é a segunda mais preferida, com metade da porcentagem de escolha da área mais preferida, e também possui caminhos estreitos. Em contraposição, as duas áreas menos preferidas 02 - Rinocerontes e 06 - Camelos, e que também possuem baixa densidade de visitantes (principalmen- 
te em permanência) apresentam caminhos largos, que passam uma sensação exagerada de amplitude. Tudo isso, somado com a falta de estímulos visuais e atividades programadas ao longo desse caminho contribuem para a avaliação negativa. Verifica-se, no jardim zoológico em estudo, que não é a largura do caminho propriamente dita que interfere no uso do espaço, mas sim o que esse caminho possui nele e ao seu redor. Se um caminho é considerado muito largo, passando uma sensação exagerada de amplitude e não apresentando estímulos visuais, ele será menos preferido pelos visitantes e terá menor uso. Ao mesmo tempo, se o caminho for considerado muito largo e possuir grande variedade de estímulos visuais e diversas atividades para os visitantes, ele será mais preferido, e terá um maior uso pelos visitantes. Em relação aos comprimentos, a necessidade de grandes caminhadas para ir de um lugar ao outro é considerada como um fator negativo do espaço, e inclusive, é um dos fatores determinantes para que a Área 06 - Camelos tenha sido considerada a menos preferida. Verifica-se assim que o comprimento dos caminhos contribui no uso dos espaços do Parque Zoológico. Caminhos muito longos tornam a visita muito cansativa e desincentivam o uso pelos visitantes.

Também foi identificado que a pavimentação dos caminhos contribui para o uso dos espaços, mas não é um fator de grande importância. Ao analisar as duas áreas mais preferidas dos visitantes, a Área 03 - Macacos, que possui caminhos com pavimentação de paralelepípedos de pedra e a Área 04 - Pássaros, que possui caminhos de chão batido, observa-se uma grande diferença no seu uso, e isso ocorre em parte devido ao tipo de pavimentação. A presença de chão batido (sem pavimentação) da Área 04 restringiu o seu uso mais intenso, ainda que esta área apresente muitos dos aspectos que os visitantes apontaram como positivos, tais como padronização dos recintos, variedade de animais e riqueza visual. A não pavimentação de uma área não é levada em consideração pelos visitantes quando há animais de grande interesse. Isso é perceptível na área 05 - Carnívoros, que mesmo não possuindo pavimentação e contando com vários problemas de acessibilidade, é uma área muito visitada, devido ao fato dos animais favoritos dos respondentes estarem nessa área de expo- sição. O mesmo acontece na área de exposição 01 - Fazenda, em que os visitantes transitam pelo caminho não pavimentado até chegar ao elefante (animal de maior interesse) e não seguem o caminho para conhecer os demais animais.

Em relação as linhas de visadas proporcionadas, verifica-se que caminhos retos, com clareza visual (linhas de visadas abertas), que permitem que o indivíduo visualize todas as possibilidades de percurso e identifique os pontos mais interessantes para si são mais utilizados do que caminhos que passam a sensação de mistério e necessitam de exploração.

\section{Considerações Finals}

Este estudo buscou identificar quais elementos paisagísticos dos espaços abertos de jardins zoológicos intensificam a preferência e uso do ambiente.

Conclui-se que a preferência por espaços abertos é influenciada principalmente pela sua riqueza visual e pela sua naturalidade (vegetação e água). Esta informação está de acordo com as afirmações de Ebenhöh (1992), de que cenas que contenham estímulos naturais, como fontes de água, lagos, árvores, arbustos e flores, que proporcionem variedade, são preferidas pelos visitantes. É necessário enfatizar, que jardins zoológicos são lugares de design imersivo, sendo a naturalidade do ambiente vista como um fator importante de avaliação.

Verificou-se também que no ambiente do Parque Zoológico, os espaços que demonstram um maior planejamento são preferidos pelos visitantes, se comparados com espaços ocasionais (não planejados). A vegetação ornamental e a pavimentação de caminhos aumentam a sensação de planejamento, e assim, aumentam o uso do ambiente. A pavimentação só não é levada em consideração para o uso de uma determinada área quando há animais de grande interesse dos visitantes. A manutenção do ambiente também se mostrou um fator importante para a preferência dos visitantes por espaços. Estas informações estão de acordo com as afirmações de Ebenhöh (1992), de que a aparência do ambiente é importante para o público. 
Sendo assim, revelam-se os aspectos paisagísticos que mais influenciam no uso dos espaços pelos visitantes. Se faz necessário agora, através de métodos auto relativos, complementar os dados dos mapas comportamentais e fazer correlações das respostas com o real uso do espaço. Espera-se que os resultados obtidos neste estudo da área de pesquisa das Relações Ambiente-Comportamento contribuam para a qualificação dos ambientes de jardins zoológicos.

\section{RefERÊNCIAS BibliográficAs}

BITGOOD, Stephen. An overview of the methodology of visitor studies. Visitor behavior, v.3, n.3. Center of Social Design. Jacksonville, Alabama, 1988.

COE, Jon. Zoo Environments for People, Plants and Animals. Workshop for Indian Zoo Direc tors, Central Zoo Authority of India: Designing Enclosures and Landscape Planning for India Zoos, India, 2011.

COE, Jon. Design and Architecture: Third Generation Conservation, Post-Immersion and Beyond. Future of Zoos Symposium, 10-11 February. Canisius College, Buffalo, New York, 2012. HANCOCKS, David. Different Nature - The paradoxical world of zoos and their uncertain future. Berkeley: University of California Press, 2003.

EBENHOH, Monica. Evaluating Zoo Design: The Importance of Visitor Studies. Dissertation (msster of landscape architecture) - University of Agricultural Sciences. Vienna, Austria, 1992.

FRANCIS, M. Urban Open Spaces: designing for user needs. Washington: Island Press, 2003.

GRAETZ, Michael. The Role of Architectural Design in Promoting the Social Objectives of Zoos. A Study of Zoo Exhibit Design with Reference to Selected Exhibits in Singapore Zoological Gardens. Dissertation (master of architecture) - University of Singapore. Singapore, 1995.

HAAS, Karen. Espaços abertos: indicadores da apropriação interna e a adaptação dos usuários do entorno. Dissertação (Mestrado em Planejamento Urbano e Regional) - Faculdade de os do entorno. Dissertação (Mestrado em Planejamento Urbano e Regional)

JONES, Grant; COE, Jon; PAULSON, Dennis (revisors). Long-Range Plan, Development Guidelines and Exhibit Scenarios. Woodland Park Zoo, Library of Congress, 1976.

REIS, Antônio; LAY, Maria Cristina. Avaliação da qualidade de projetos - uma abordagem perceptiva e cognitiva. Revista Ambiente Construído, Porto Alegre, v. 6, n.3, p. 21-34, 2006. YIN, Robert. Estudo de caso: Planejamento e métodos. GRASSI, D. (Trad.), $2^{\mathrm{a}}$ ed. Porto Alegre: Bookman, 2001.

\section{Samantha Balleste}

Universidade Federal de Pelotas, Faculdade de Arquitetura e Urbanismo. Rua Benjamin Constant, n. 1359, Pelotas, Rio Grande do Sul, Brasil.

CV: http://lattes.cnpq.br/9882350286420290

Orcid: https://orcid.org/0000-0002-8366-2928

E-mail: samantha_balleste@hotmail.com

\section{Natalia Naoumova}

Universidade Federal de Pelotas, Faculdade de Arquitetura e Urbanismo.

Rua Benjamin Constant, n. 1359, Pelotas, Rio Grande do Sul, Brasil.

CV: http://lattes.cnpq.br/0767079956550417

Orcid: https://orcid.org/0000-0002-8180-5454

E-mail: naoumova@gmail.com

Nota do Editor:

Revisão do texto. Sandra Alves, Núcleo de revisão de textos UFPe

Submetido em: 19/08/2018 